\title{
Creep Behavior of Thick and Thin Walled Structures of a Single Crystal Nickel-Base Superalloy at High Temperatures - Experimental Method and Results
}

\author{
Rainer Hüttner ${ }^{1)}$, Rainer Völk1 ${ }^{1)}$, Johannes Gabel ${ }^{2)}$, Uwe Glatzel ${ }^{1)}$ \\ ${ }^{1)}$ Metals and Alloys, University Bayreuth, D - 95440 Bayreuth, Germany \\ ${ }^{2)}$ MTU Aero Engines, Dachauer Str. 665, D - 80995 Munich, Germany \\ uwe.glatzel@uni-bayreuth.de
}

Keywords: thickness, single crystal, creep, coating,

\begin{abstract}
Creep behavior of the single crystal nickel-base superalloy René N5 is investigated as a function of material thickness. The results point out that reducing the thickness from 1.0 to $0.2 \mathrm{~mm}$ leads to both shorter creep lives and much higher overall creep strain rates of thin specimens. The orientation of the specimen is an important factor too but has a weaker influence on creep behavior under the given test conditions than the specimen thickness.
\end{abstract}

\section{Introduction}

Single crystal nickel-base superalloys are used in blades and vanes of stationary gas turbines and aero engines. Their lifetimes are mainly limited by fatigue, creep and hot corrosion at elevated service temperatures. To increase lifetime a possible strategy is to reduce the material temperature by cooling. In order to optimize both the cooling efficiency and the weight of fast rotating turbine blades a general trend is to reduce the wall thickness of the hollow investment casting parts.

The relation between creep properties and section thickness was rarely investigated [1-10]. For the polycrystalline nickel-base superalloy PWA 1484 Duhl [1] found a five fold reduction of creep rupture life if the specimen thickness is diminishing from 4 to $0.5 \mathrm{~mm}$ which mainly depends on grain size and micro structural defects. Doner and Heckler [3, 4] observed in uncoated single crystal CMSX-3 a $30 \%$ loss in creep rupture life if the wall thickness was reduced from 3.18 to $0.76 \mathrm{~mm}$ at $982^{\circ} \mathrm{C}$ and if the stress level was below $275 \mathrm{MPa}$. They also found that the time to reach $1 \%$ strain was unaffected by wall thickness at a constant stress level. Seetharaman and Cetel [6] reported similar results for single crystal PWA 1484 with wall thicknesses of 1.76 and $0.38 \mathrm{~mm}$ respectively and stresses below $275 \mathrm{MPa}$ at $982^{\circ} \mathrm{C}$. They concluded that oxidation and the more constrained plastic deformation are the major contributions for early failure of thin specimens. Doner and Heckler [3, 4] found that creep rupture properties of aluminized nickel-base superalloys are less influenced by the specimen thickness. By contrast Seetharaman and Cetel [6] mentioned a loss of creep rupture lifetime of 30$40 \%$ with a thickness reduction from 1.52 to $0.25 \mathrm{~mm}$ for coated Knowledge and understanding of the creep behavior is a fundamental prerequisite for component life-time predictions. Therefore the effect of thickness reduction on the creep properties of uncoated and aluminized single crystal nickel-base superalloy René N5 is investigated in this study. In addition deviations from the [001] orientation are incorporated into this study which is part of a ongoing research carried out for the next years.

\section{Experimental}

A cast and standard heat treated single crystal plate of the size $200 \times 65 \times 21 \mathrm{~mm}^{3}$ of René N5 was provided. Chemical composition can be found in [11]. The plate was oriented by Laue back scattered diffraction and several slices with an angle of $16^{\circ}$ off the
[001] zone axis towards the $<011>$ direction and in exact [001] orientation were cut by wire electrical discharge machining. The $16^{\circ}$ off [001] orientation was chosen in order to optimize the number of sample output. Observations of Sass et al. [12] have shown that the influence of orientation deviation towards the $<011>$ direction is less severe than deviation towards the $<111>$ direction. Two series of thick and thin tension specimens (geometries $95 \times 3 \times 1 \mathrm{~mm}^{3}$ and $95 \times 4 \times 0.2 \mathrm{~mm}^{3}$ respectively) were cut from the $16^{\circ}$ off [001] slice and two specimen series (geometries $95 \times 3 \times 1 \mathrm{~mm}^{3}$ and $95 \times 4 \times 0.3 \mathrm{~mm}^{3}$ respectively) were cut from the [001] oriented slice.

Specimens were tested with an $40 \mu \mathrm{m}$ aluminum coating and without coating. Aluminum coating was carried out by an aluminum pack cementation process $\left(>900^{\circ} \mathrm{C}\right)$ with subsequent heat treatment $\left(730^{\circ} \mathrm{C}\right.$ for $\left.24 \mathrm{~h}\right)$, for details see [13]. The initial cross section of the non-coated sample was used to calculate the necessary load for both non-coated and aluminized samples. Thereby we assume that the coating itself is not a load-bearing structure and take into account that the amount of loading on a turbine blade is independent of coating. Fig. 1 shows part of the cross section of a aluminized $0.2 \mathrm{~mm}$ specimen.

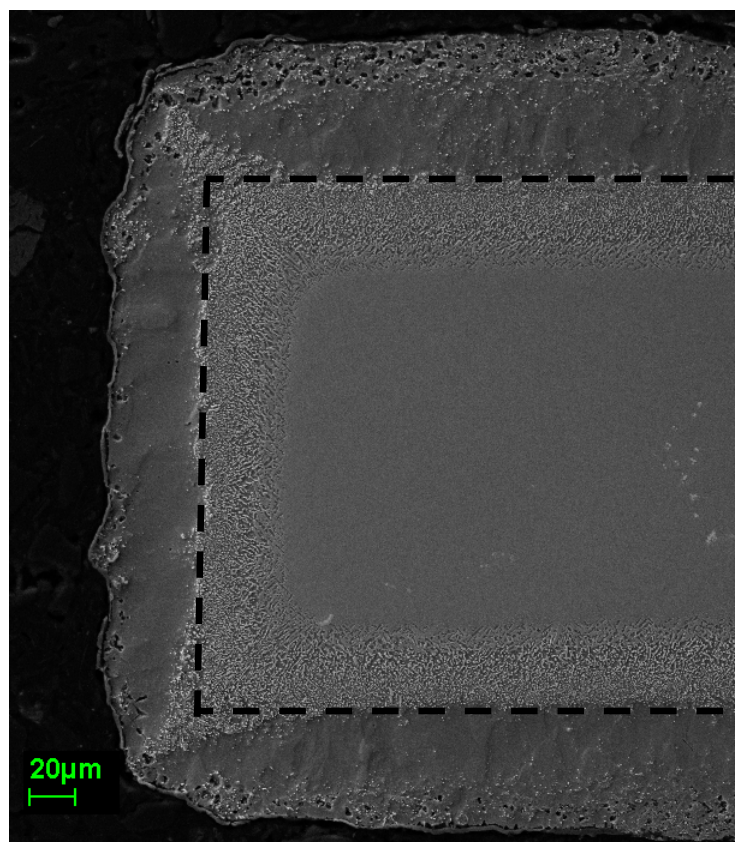

Fig. 1: Low magnification microstructure of a cross section from an aluminized sample with $0.2 \mathrm{~mm}$ original thickness. The initial cross section, indicated by a dashed line, was used to calculate the load for creep testing. 


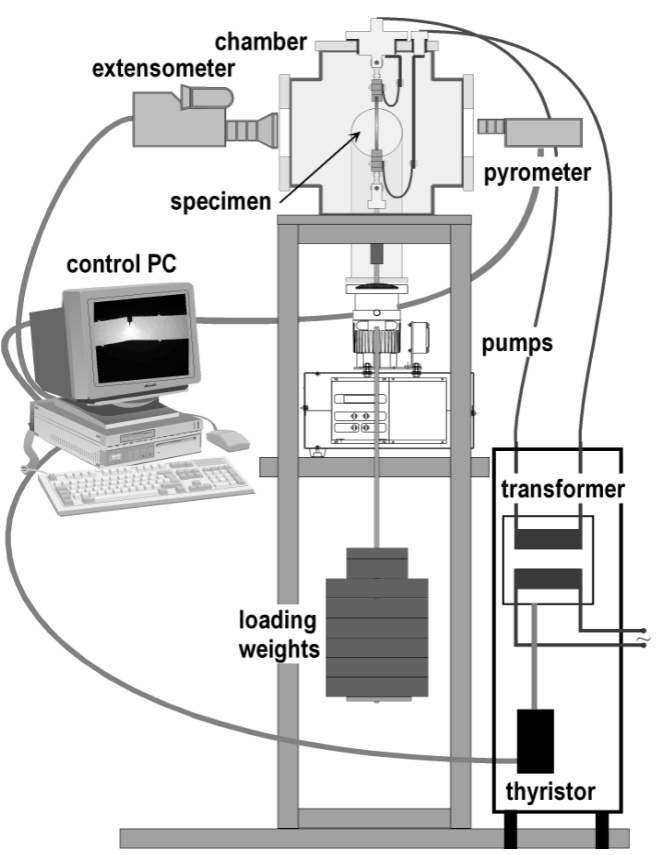

Fig. 2: Scheme of ultra-high temperature test facility.

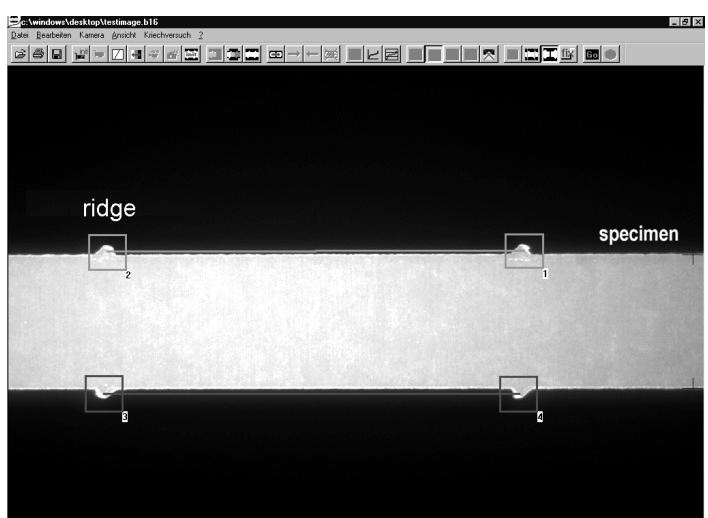

a)

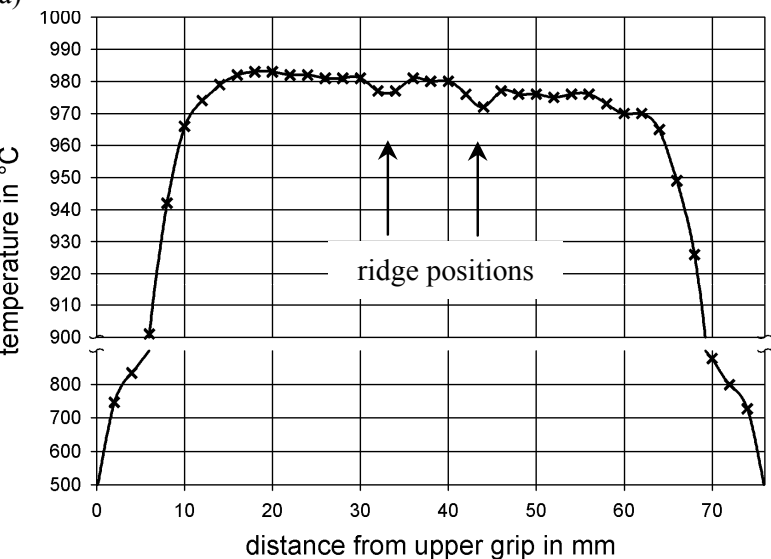

b)

Fig. 3:

a) Bright specimen at $980^{\circ} \mathrm{C}$ with 4 ridges for strain measurement.

b) Temperature distribution along a René N5 specimen. The distance between grips was $75 \mathrm{~mm}$.
Constant load tensile creep test were performed at $980^{\circ} \mathrm{C}$ for three stress levels, 230, 270 and $300 \mathrm{MPa}$ till rupture of the specimens. Proprietary test facilities with Ohmic heating [14-17] were used in this study. The test facilities permit tests either in air, vacuum or under a protective gas atmosphere. A scheme of the test facilities is given in Fig. 2. Strain between ridges in the central zone of the specimen (Fig. 3a) is measured with sub pixel accuracy by means of a CCD camera controlled by the software SuperCreep [14-17]. At a maximum measurable strain of $\varepsilon \approx 60 \%$, an error of $\Delta \varepsilon \approx \pm 7 \cdot 10^{-4}$ for a single strain measurement was determined $[15,16]$. By mean filtering over about 1500 single measurements or $60 \mathrm{~s}$ respectively an error of the mean strain of $\Delta \bar{\varepsilon} \approx \pm 3 \cdot 10^{-5}$ was deduced [16].

Temperature is controlled with a dual color pyrometer to overcome problems due to unknown emissivity. The temperature distribution at the specimen was measured by a second pyrometer (Fig. 3b). The temperature at the specimen centre was $980^{\circ} \mathrm{C}$ whereas at the ridges slightly lower temperatures of about $975^{\circ} \mathrm{C}$ were measured. In a zone $30 \mathrm{~mm}$ around the specimen centre the temperature was $980 \pm 5^{\circ} \mathrm{C}$.

\section{Results}

Creep tests on $16^{\circ}$ off [001] oriented René N5 specimens $0.2 \mathrm{~mm}$ as well as $1 \mathrm{~mm}$ thick specimens show typical creep curves with decreasing creep rate until minimum creep rates are reached followed by steadily increasing creep rate (Fig. 4, 5 and 6). Minimum creep rates of thin specimens are about one order of magnitude higher than $1.0 \mathrm{~mm}$ thick specimens. Strain to failure remained below $5 \%$ for $0.2 \mathrm{~mm}$ thick specimens under all applied loads, whereas fracture strains were always above $20 \%$ for $1 \mathrm{~mm}$ thick specimens (Fig. 6). By reduction of specimen thickness from 1 to $0.2 \mathrm{~mm}$ the creep rupture life is reduced by a factor of 4 to 5 .

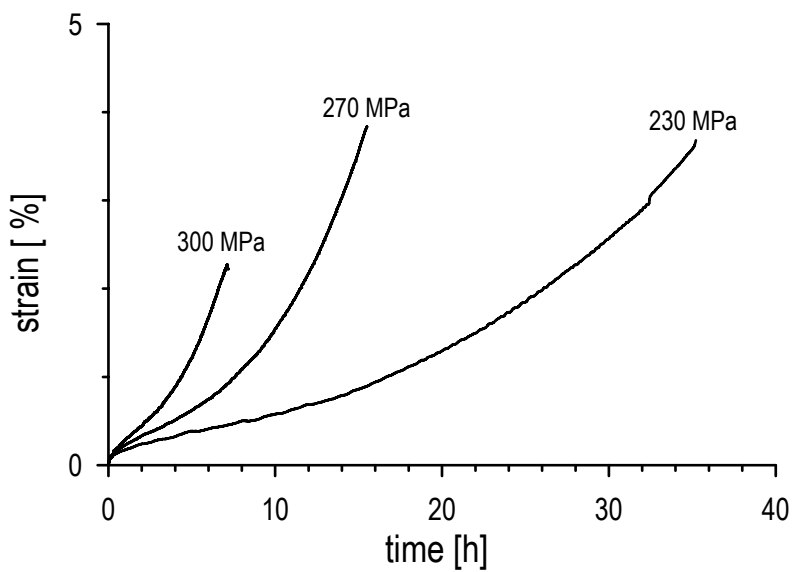

Fig. 4: Strain vs. time creep curves René N5, $16^{\circ}$ off [001], $0.2 \mathrm{~mm}, 980^{\circ} \mathrm{C}$. 


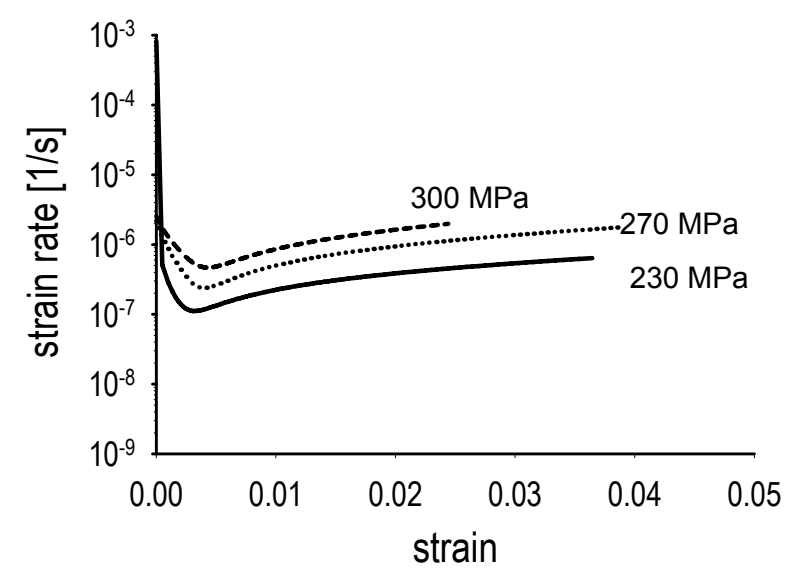

Fig. 5: Strain rate vs. strain creep curves, René N5, $16^{\circ}$ off [001], $0.2 \mathrm{~mm}, 980^{\circ} \mathrm{C}$.

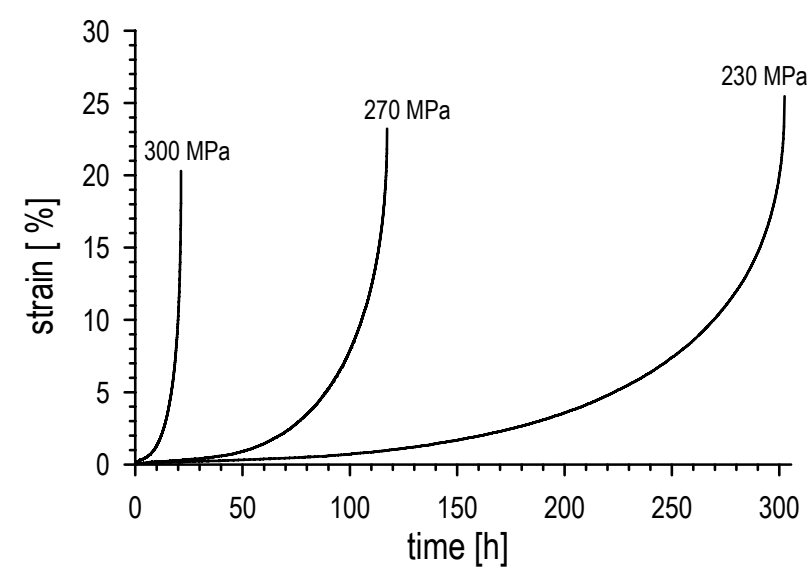

Fig. 6: Strain vs. time creep curves, René N5, $16^{\circ}$ off [001], $1.0 \mathrm{~mm}, 980^{\circ} \mathrm{C}$.

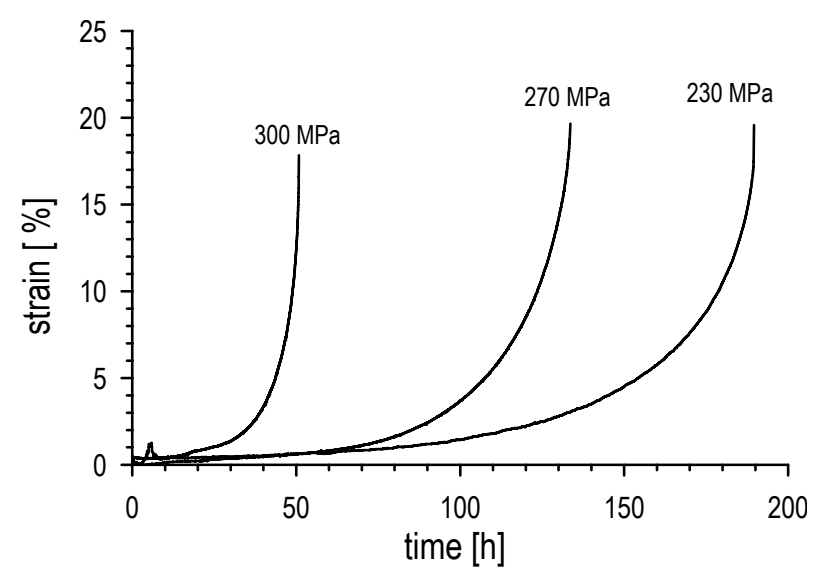

Fig. 7: Strain vs. time creep curves, René N5, $16^{\circ}$ off [001], aluminized, $1.0 \mathrm{~mm}, 980^{\circ} \mathrm{C}$.

Creep tests on $16^{\circ}$ off $[001]$ oriented and aluminized René N5 specimens

Fig. 7 shows the creep behavior of $1.0 \mathrm{~mm}$ thick samples with aluminized coating. A comparison between aluminized and not aluminized specimens (Fig. 6 and 7) reveals no systematic improvement in rupture times for coated $1 \mathrm{~mm}$ thick samples.

\section{Creep tests on [001] oriented René N5 specimens}

Results for specimens oriented in perfect [001] orientation without coating are presented in Fig. 8 and 9. Specimen thickness has also an influence on creep rupture time and rupture strain for [001] orientation, however the effect is strongest at low stress of $230 \mathrm{MPa}$ where the time to reach $1 \%$ strain is reduced by a factor of 2 from $1 \mathrm{~mm}$ to $0.3 \mathrm{~mm}$ thickness. Rupture strains of $0.3 \mathrm{~mm}$ thick specimens were generally lower than for $1.0 \mathrm{~mm}$ thick specimens while minimum creep rates do not change significantly for the same load (compare Fig. 8 and 9).

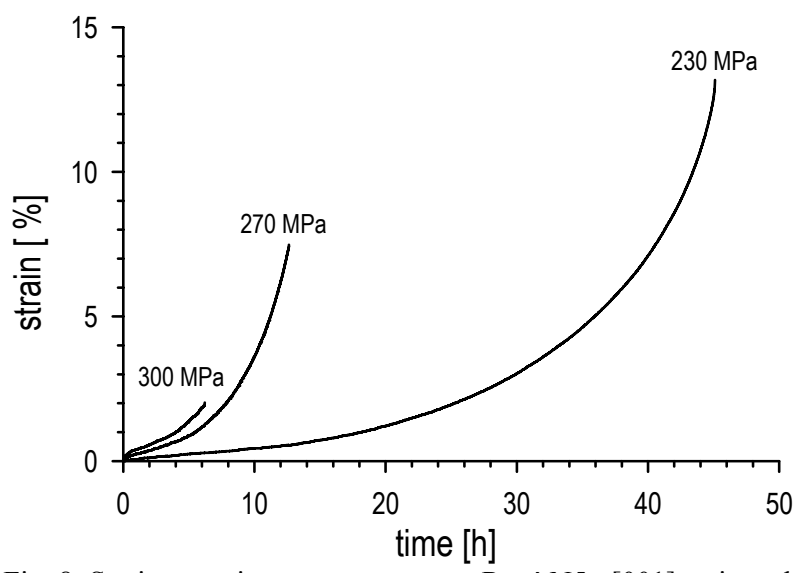

Fig. 8: Strain vs. time creep curves, René N5, [001] oriented, $0.3 \mathrm{~mm}, 980^{\circ} \mathrm{C}$

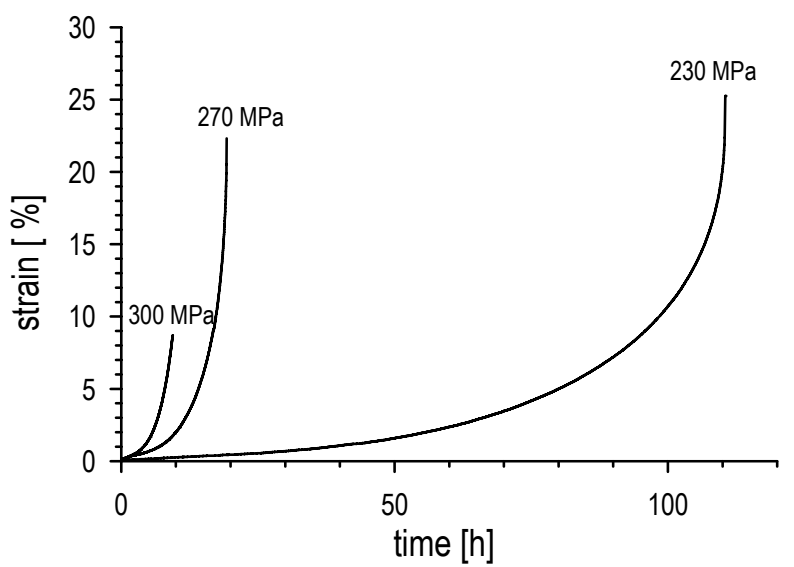

Fig. 9: Strain vs. time creep curves, René N5, [001] oriented, $1.0 \mathrm{~mm}, 980^{\circ} \mathrm{C}$

Creep test on [001] oriented and aluminized René N5 specimens Comparing Fig. 10 and Fig. 11 reveals that $1 \mathrm{~mm}$ thick aluminized specimens reach higher rupture strains and lower creep rates than $0.3 \mathrm{~mm}$ thick samples. All $1 \mathrm{~mm}$ thick specimens rupture after reaching about $20 \%$ strain. Thin samples only reach $5 \%$. Minimum creep rates of thick samples are lower than for thin samples. Aluminized and [001] oriented samples show higher creep rupture times and lower minimum creep rates than not aluminized samples if the stress was referred to the remaining cross sectional area without the coating. 


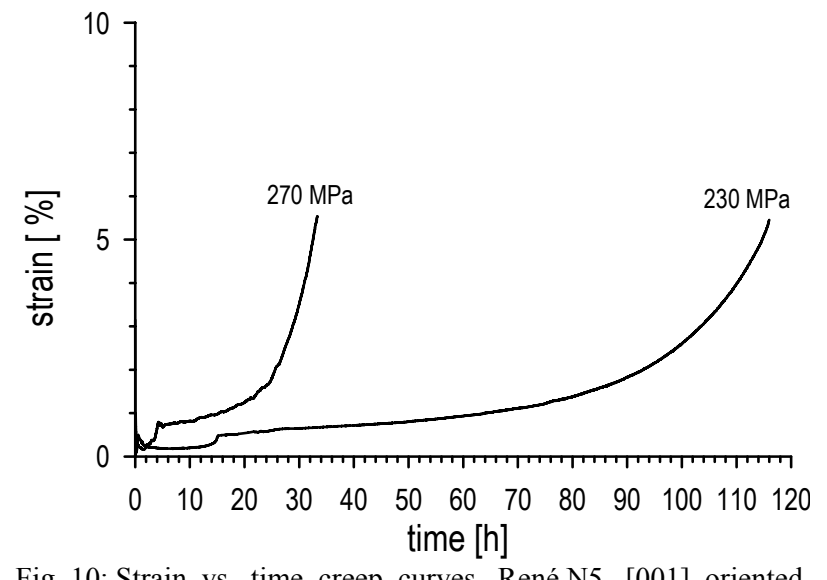

Fig. 10: Strain vs. time creep curves, René N5, [001] oriented, aluminized, $0.3 \mathrm{~mm}, 980^{\circ} \mathrm{C}$

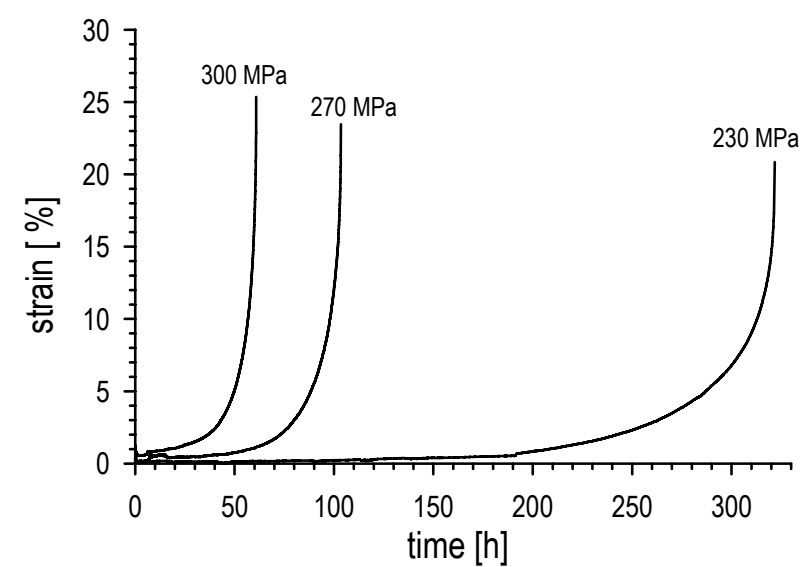

Fig. 11: Strain vs. time creep curves, René N5, [001] oriented, aluminized, $1.0 \mathrm{~mm}, 980^{\circ} \mathrm{C}$

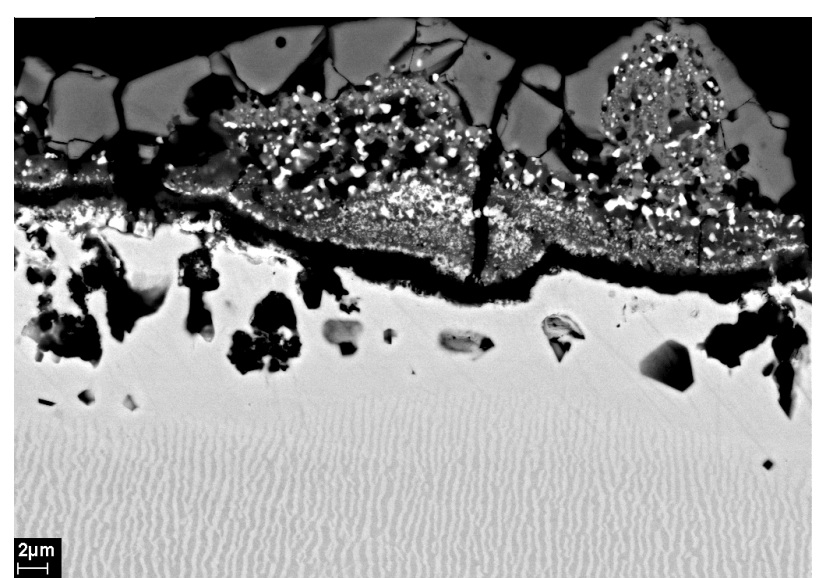

Fig. 12: Microstructure of coated sample after creep testing $\left(230 \mathrm{MPa}, 980^{\circ} \mathrm{C}, 115 \mathrm{~h}\right)$.

First microstructural investigations

Fig. 12 shows a cross section of a $0.3 \mathrm{~mm}$ aluminized sample crept at $230 \mathrm{MPa}$ at $980^{\circ} \mathrm{C}$. Clearly the raft structure of the René N5 substrate is visible in the lower part of the micrograph (stress axis horizontal). Followed by a $\gamma^{\prime}$ free zone and layers of different oxide types.

\section{Discussion}

Creep results for rupture life and minimum creep rates are summarized in Table 1. The results indicate that the creep behavior is strongly influenced by the surface to volume ratio of the specimens.

Table 1: Data for rupture lifetime [h]/minimum creep rate $\left[10^{-9} \mathrm{~s}^{-1}\right]$ as function of thickness and coating for René N5 single crystals at $980^{\circ} \mathrm{C}$ testing temperature

\begin{tabular}{|c|l|c|c|c|}
\hline $\begin{array}{c}\text { Wall- } \\
\text { thickness } \\
{[\mathrm{mm}]}\end{array}$ & $\begin{array}{l}\text { Stress } \\
\text { levels } \\
{[\mathrm{MPa}]}\end{array}$ & $\begin{array}{c}16^{\circ} \text { off } \\
{[001]}\end{array}$ & $\begin{array}{c}{[001]} \\
\text { oriented }\end{array}$ & {$[001]$ oriented } \\
\hline \multirow{3}{*}{$0.2 / 0.3$} & 230 & $35 / 112$ & $45 / 71$ & $115 / 29$ \\
\cline { 2 - 5 } & 270 & $16 / 239$ & $12 / 383$ & $33 / 122$ \\
\cline { 2 - 5 } & 300 & $7 / 467$ & $6 / 391$ & \\
\hline \multirow{3}{*}{1} & 230 & $302 / 2.4$ & $110 / 59$ & $321 / 5.4$ \\
\cline { 2 - 5 } & 270 & $117 / 19$ & $19 / 376$ & $103 / 17.4$ \\
\cline { 2 - 5 } & 300 & $21 / 117$ & $9 / 485$ & $60 / 73$ \\
\hline
\end{tabular}

The time to reach $1 \%$ creep strain is more reliable to reveal tendencies than creep rupture lives. It is mentioned in $[3,4,6]$ that the time to reach $1 \%$ strain is independent of wall-thickness. This is the case in our tests only for the higher stress level of $300 \mathrm{MPa}$. Lower stress levels indicate a strong dependence of the time to reach $1 \%$ strain on specimen thickness, both for non-coated and aluminized samples.

For [001] oriented René N5 specimens the time to reach 1\% creep strain was roughly equal for not aluminized specimens for all levels tested here (Fig. 13). For aluminized specimens the time to reach $1 \%$ creep strain was dependent on wall-thickness.

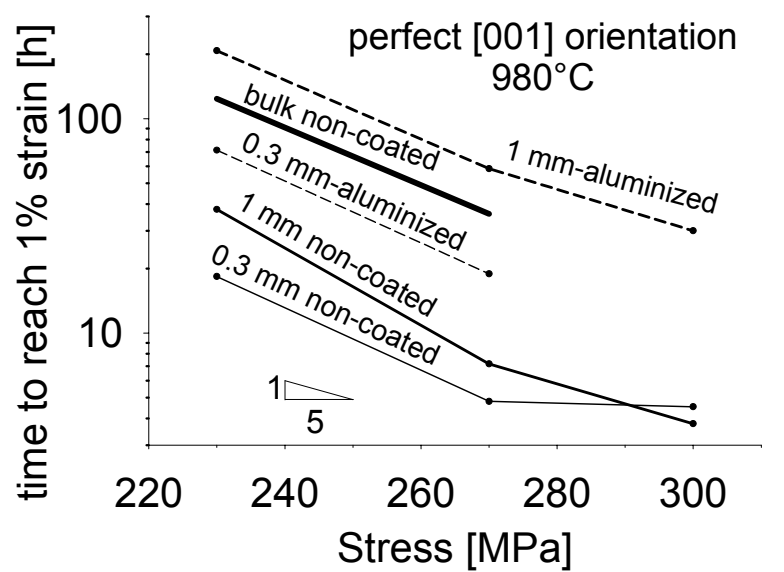

Fig. 13: René N5 with [001] orientation. Time to reach $1 \%$ creep strain.

\section{Conclusions}

The creep behavior of single crystal René N5 at $980^{\circ} \mathrm{C}$ was investigated as function of sample thickness, orientation and coating conditions.

- The creep behavior of $16^{\circ}$ off [001] compared to perfect [001] orientation at the test temperature of $980^{\circ} \mathrm{C}$ are similar. 
- First results point out that reducing the wall thickness from 1.0 to 0.2 or $0.3 \mathrm{~mm}$ leads to lower creep rupture strains, lower life times and higher minimum creep strain rates.

- Non-coated René N5 specimens are strongly influenced by thickness changes with about $1 / 5$ of the time to reach $1 \%$ strain in comparison to bulk samples.

- Aluminized samples show in general better creep resistance than non-coated samples with same original cross section. Stress was determined by the net-cross section of the sample without coating.

Further investigations to improve the statistics (repeated creep tests) will be carried out in the near future to eliminate material scatter. Microstructural observations especially of surface features will be carried as described in [13] in order to further understand the mechanics leading to these observations.

\section{Acknowledgements}

The authors gratefully acknowledge financial support by the Deutsche Forschungsgemeinschaft (German Research Foundation), DFG through Graduiertenkolleg GRK 1229 and Forschergruppe FOR 727.

\section{References}

[1] D.N. Duhl: "Directional Solidified Superalloys", in Superalloys II, C.T. Sims, N.S. Stoloff, and W.C. Hagel, (Eds.), (John Wiley, New York, 1987), 189-214

[2] P.J. Henderson: "Creep of coated and uncoated thin section CMSX - 4", Materials for Advanced Power Engineering (Forschungszentrum Juelich GmbH, 1998), 1559-1568

[3] M. Doner and J.A. Heckler: "Effects of Section thickness and Orientation on creep rupture properties of two advanced single crystal alloys", in SAE Technical Paper 851785 , (Society of Automotive Engineers Inc., 1985)

[4] M. Doner and J.A. Heckler: "Identification of Mechanisms responsible for Degradation in thin-wall stress rupture properties", in Superalloys 1988, Proceedings of the $6^{\text {th }}$ International Symposium on Superalloys (The Metallurgical Society, Warrendale, PA, 1988), 653-662,

[5] N. Roy and R.N. Ghosh: "Modelling effects of specimen size and shape on creep of metals and alloys", Scripta Materialia, 36 (12) (1997), 1367-1372,

[6] V. Seetharaman and A.D. Cetel: "Thickness debit in creep properties of PWA 1484" in Superalloys 2004, ed K. A. Green et al., (TMS,2004), 207-214,

[7] M.C. Pandey and D.M.R. Taplin: "Prediction of lifetime in thin sections of a nickel base superalloy", Scripta Metallurgica et Materialia, 31 (6) (1994), 719-722,

[8] P.J. Henderson: "Creep of single crystal Ni-base superalloy in thick and thin section forms" in Creep and Fracture of Engineering materials and structures, ed. J.C. Earthman and F.A. Mohamed, (1997), 697-706

[9] A. Baldan: "On the thin-section size dependent creep strength of a single crystal nickel-base superalloy", Journal of Materials Science, 30 (1995), 6288-6298,

[10] A. Baldan: "Combined effects of thin-section size, grain size and cavities on the high temperature creep fracture properties of a nickel-base superalloy, Journal of Materials Science, 32 (1997) 35-45,

[11] Y. Koizum: "Database of Creep Propertiy for Nickel-Base Single Crystal Superalloys, RenéN4, RenéN5 and CMSX-4", Journal of Japan Inst. Metals, 40 (2) (2006), 176-179
[12] V. Sass, U. Glatzel, M. Feller-Kniepmeier:“ Anisotropic creep properties of the Nickel-base superalloy CMSX-4", Acta materialica, 44 (5) (1996), 1967-1977

[13] S. Wöllmer, T. Mack, M. Göken, S. Zaefferer, U. Glatzel:

"Characterization of Phases of Aluminized Nickel Base Superalloys", Surface and Coating Technology, 167 (2003), 83-96 [14] R. Völkl, D. Freund, B. Fischer: "Economic Creep Testing of Ultra-High Temperature Alloys", Journal of Testing \& Evaluation, 31 (1) (2003), 35-43

[15] R. Völkl, B. Fischer: "Mechanical Testing of Ultra-High Temperature Alloys", Experimental Mechanics, 44 (2) (2004), 121-127

[16] R. Völkl, , B. Fischer, M. Beschliesser and U. Glatzel, „Evaluating strength at ultra-high temperatures - methods and results“ Materials Science \& Engineering A, in press 2008

[17] B. Fischer, S. Vorberg, R. Völkl, M. Beschliesser, A. Hoffmann: "Creep and tensile tests on refractory metals at extremely high temperatures", Int. Journal of Refractory Metals \& Hard Materials, 24 (2006), 292-297 